Enf Neurol (Mex)

Vol. 11, No. 1: 47-52, 2012

Ensayo

CINNN, 2010

\title{
Reflexiones sobre la despenalización del aborto en México
}

\author{
Fernando Trejo Martínez*
}

\begin{abstract}
RESUMEN
Hace aproximadamente cinco años, se aprobó por la Asamblea de Representantes del Distrito Federal la despenalización del aborto en el D. F. Esta situación hace reflexionar acerca de la condición moral y ética de los representantes que elegimos para que salvaguardaran nuestros intereses en la Cámara de Diputados. ¿A quién le preguntaron si estábamos de acuerdo con la modificación del Código Penal? ¿Cómo influirá en la práctica de enfermería esta nueva ley que obliga a las enfermeras a participar en actos contrarios a sus creencias y principios? ¿Dónde quedó el respeto al derecho de objeción de conciencia de los profesionales de salud? Son preguntas que quedarán por resolverse. Lo que sí es necesario hacer es un análisis de la situación desde el punto de vista ético-legal, y las implicaciones que acarrea para la práctica profesional. El presente ensayo hace una reflexión sobre los aspectos éticos y morales que se deben de cuestionar las enfermeras cuando les toque enfrentar alguna situación como la que se está tratando; así mismo, se realizará un resumen de las leyes, tanto nacionales como internacionales que protegen al no nacido y que fueron pasadas por alto para aprobar el decreto que despenaliza al aborto en el Distrito Federal.
\end{abstract}

Palabras clave: Aspectos éticos, moral persona, respeto, aborto.

\section{Reflections on the decriminalization of abortion in Mexico}

\begin{abstract}
About five years ago, was approved by the Representatives Assembly of the Federal District, the legalization of abortion in D. F. This situation does reflect on the moral and ethical representatives who chose to have safeguarded our interests in the House of Representatives, because who asked if we agreed with the amendment of the penal code? How to influence nursing practice this new law requiring nurses to participate in acts contrary to their beliefs and principles? What happened to respect the right of conscientious objection by health professionals? This are questions that remain to be resolved. What if you need to do is analyze the situation from the standpoint of legal ethics, and carries implications for professional practice. This paper will make a beginning of reflection on the ethical and moral question that must be nurses when they touch face a situation such as being treated, and it will be a summary of the laws, both national and international protect the unborn and that were overlooked in order to pass the decree decriminalizing abortion in Mexico City.
\end{abstract}

Key words: Ethical, moral person, respect, abortion.

* Maestría en Enfermería en Educación.

Correspondencia: Fernando Trejo Martínez. Insurgentes Sur Núm. 3877, Col. La Fama, 14269, Delegación Tlalpan, México, D.F. E-mail:fertre001@yahoo.com

Este artículo puede ser consultado en versión completa en http://www.medigraphic.com/enfermerianeurologica 


\section{Análisis de la situación}

$\mathrm{U}$ no de los principios fundamentales de enfermería es preservar la vida; por lo tanto, diversas teórias destacan también, en sus postulados, la relación interpersonal y el respeto a la persona ${ }^{1,2}$ fundamentando con esto los principios de la ética personalista, que promueve el reconocimiento de la persona y los derechos de la misma por el solo hecho de serlo. ${ }^{3-5}$

Pero ¿desde cuándo se es persona?, es una pregunta que requiere un minucioso análisis ontológico, ${ }^{6}$ y que de haber podido resolverla nuestros representantes ante el congreso, no hubieran aprobado el decreto para despenalizar el aborto. Lo cierto es que desde hace mucho tiempo este debate se ha dado entre los defensores de la vida del ser humano y los defensores de los derechos humanos, contra los que promueven, desde el aborto, la investigación con embriones humanos y los que protegen los intereses de las industrias farmacéuticas de anticonceptivos y abortivos; ${ }^{7}$ sin embargo, resulta fácil (para alguien que ha consultado a diversos autores que defienden la postura de que la vida comienza desde el mismo instante de la fecundación) tomar partido por la defensa de la vida del embrión humano y su respeto como persona desde el principio del embarazo, y mucho antes de nacer. ${ }^{8}$

El debate sobre la corporeidad del embrión humano ha existido desde los inicios de la historia; ${ }^{9}$ desde Aristóteles, hasta nuestros días se ha discutido, sobre desde cuándo el embrión puede considerarse humano, ${ }^{10}$ dilema ontológico que no se ha podido resolver hasta nuestros días y que se ha tomado como pretexto de los defensores de la experimentación con embriones humanos; ${ }^{11} \sin$ embargo, éste no fue el debate sobre la despenalización del aborto en el D. F., más bien fue promover el aborto desde la perspectiva de la clandestinidad del mismo, lo que provocaba muertes por prácticas antisanitarias y con escasos conocimientos de quienes los practicaban; también se exageró sobre el número de muertes provocadas por la práctica del aborto, apelando, además, a grupos pro defensa de la mujer, que sin conocimiento de causa, y manipulados por ciertos grupos parlamentarios, ${ }^{12}$ con ciertos fines netamente partidistas y sensacionalistas, apelaron sobre el bien de la mujer sin tomar en cuenta al embrión, faltando al elemental principio de la ética y bioética que es la del respeto a la vida, no importando en qué estadio o periodo se encuentre. ${ }^{13}$

Antes de continuar, es conveniente definir qué es la objeción de conciencia: "el rechazo de someterse a una norma, una disposición de ley que se considera injusta, en cuanto que se opone a la ley natural, es decir, fundamental en la vida humana, y percibida como tal en la conciencia", ${ }^{14}$ por principio de cuentas, los profesionales de enfermería están formados con una gran carga de teorías y modelos que les fomentan el respeto al ser humano; por lo tanto, a la vida como a la preservación de la salud.

\section{Determinación del problema}

La participación de la enfermera en actos que no son acordes a sus premisas éticas, juramentos y creencias, al ser obligadas a participar en la realización de un aborto, y que no tienen derecho a la objeción de conciencia. A continuación se enumeraran los códigos y leyes que la enfermera estará violando cuando se le obligue a participar en esta situación. Si bien el Código Ético para Enfermeras dictado por el Colegio Mexicano de Licenciados en Enfermería, A.C. dice en el capítulo segundo, de los deberes y responsabilidades de las enfermeras para con las personas,

Artículo $2^{\circ}$ Respeta la vida, los derechos humanos y por consiguiente el derecho de la persona a decidir tratamientos y cuidados una vez informado. Artículo $3^{\circ}$ Mantener una relación estrictamente profesional con la persona, en un ambiente de respeto mutuo y de reconocimiento de su dignidad, valores, costumbres y creencias.

Artículo $4^{\circ}$ Proteger la integridad de la persona ante cualquier afectación ocasionada por la mala práctica de cualquier miembro del equipo de salud. Artículo $5^{\circ}$ Mantener una conducta honesta y leal; conducirse con una actitud de veracidad y confidencialidad salvaguardando en todo momento los intereses de la persona.

Artículo $6^{\circ}$ Comunicar a la persona los riesgos cuando existan, y los límites que tiene el secreto profesional ante circunstancias que impliquen mala intención o daño a terceros. Artículo $7^{\circ}$ Fomentar una cultura de autocuidado de la salud, con un enfoque anticipatorio y de prevención del daño, y propiciar un entorno seguro que prevenga riesgos y proteja a la persona.

Artículo $8^{\circ}$ Otorgar a la persona cuidados libres de riesgos, manteniendo un nivel de salud física, mental y social que no comprometa su capacidad.

Artículo $14^{\circ}$ Prestar sus servicios al margen de cualquier tendencia xenófoba, racista, elitista, política o bien por la naturaleza de la enfermedad.

Artículo $17^{\circ}$ Actuar con juicio crítico en la aplicación de las normas institucionales, tomando en cuenta la objeción de conciencia.

\section{Capítulo quinto. De los deberes de las enfermeras para con su profesión}

Artículo $2^{\circ}$ Mantener el prestigio de su profesión, mediante el buen desempeño del ejercicio profesional. 


\section{DEL DECÁLOGO DEL CÓDIGO DE ÉTICA}

1. Respetar y cuidar la vida y los derechos humanos, manteniendo una conducta honesta y leal en el cuidado de las personas.

2. Proteger la integridad de las personas ante cualquier afectación, otorgando cuidados de enfermería libres de riesgos. 3. Asumir la responsabilidad como miembro del equipo de salud, enfocando los cuidados hacia la conservación de la salud y prevención del daño.

4. Pugnar por el desarrollo de la profesión y dignificar su ejercicio.

\section{Código Deontológico del Consejo Internacional} de Enfermeras para la Profesión de Enfermería

1. Las enfermeras tienen cuatro deberes fundamentales: promover la salud, prevenir la enfermedad, restaurar la salud y aliviar el sufrimiento. La necesidad de enfermería es universal.

2. Son inherentes a la enfermería el respeto de los derechos humanos, incluido el derecho a la vida, a la dignidad y a ser tratado con respeto. 3. En los cuidados de enfermería no se hará distinción alguna fundada en consideraciones de edad, color, credo, cultura, discapacidad o enfermedad, género, nacionalidad, opiniones políticas, raza o condición social.

\section{Del Código Civil}

Art. 22: Entra bajo la protección de la ley el concebido y no nacido. Lo denomina individuo, como en la Constitución. Art. 1314: El concebido y no nacido tiene derecho a heredar. Arts. 1638 y 1643: Los no nacidos detienen y modifican las obligaciones alimentarías hasta su nacimiento. Art. 1648: Los concebidos suspenden la partición de la herencia. Art. 2357: Los no nacidos pueden recibir donaciones.

\section{Del Derecho Constitucional}

Art. 1 ${ }^{\circ}$ : Todo individuo gozará de las garantías que otorga esta Constitución. Art. 14: Nadie podrá ser privado de la vida. Art. 16: Nadie puede ser molestado en su persona, familia... sino en virtud de mandamiento escrito de la autoridad competente, que funde y motive la causa legal del procedimiento. Ninguna ley o autoridad puede decretar la muerte de un individuo mas que en casos establecidos en el Art. 22 de la Constitución.

Art. 22 ( $4^{\circ}$ párrafo): Queda también prohibida la pena de muerte por delitos políticos, y en cuanto a los demás, sólo podrá imponerse: al traidor a la Patria en guerra extranjera, al parricida, al homicida con alevosía, premeditación o ven- taja, al incendiario, al plagiario, al salteador de caminos, al pirata y a los reos de delitos graves del orden militar.

\section{Tratados internacionales}

Se convierten en derecho interno vigente y se encuentran sobre las leyes locales y federales. Declaración de Ginebra de 1924. Firmado en New York, 9 Dic. 1948 y ratificada en Diario Oficial el 11 Oct. 1948. Sobre prevención y castigo de genocidio. Art. II inciso d): Medidas destinadas a impedir los nacimientos en el seno de un grupo (nacional, étnico, racial o religioso).

Declaración Universal de los Derechos Humanos, 1948. Art. $3^{\circ}$, pertinente al derecho a la vida. Art 6. "Todo ser humano tiene derecho, en todas partes, al reconocimiento de su personalidad jurídica."

Declaración de los Derechos del Niño, 1959: Considerando que el niño, por su falta de madurez física o mental, necesita protección y cuidados especiales, incluso la debida protección legal, tanto antes como después del nacimiento.

Principio 4: El niño gozará de los beneficios de la seguridad social. Tendrá derecho a crecer y desarrollarse en buena salud; con este fin deberán proporcionarse, tanto a él como a su madre, cuidados especiales, incluso atención prenatal y postnatal.

\section{Convención Americana sobre los Derechos Humanos, 1981}

Art. $4^{\circ}$ Derecho a la vida. Toda persona tiene derecho a que se respete su vida. Este derecho estará protegido por la ley y, en general, a partir del momento de la concepción. Nadie puede ser privado de la vida arbitrariamente.

\section{LEY GENERAL DE SALUD}

\section{Reglamento en Materia de Investigación para la Salud}

Art. 40. Especifica algunos términos, para los efectos de este reglamento, se entiende por:

Embarazo: Periodo comprendido desde la fecundación del óvulo hasta la expulsión o extracción del feto y sus anexos.Embrión: El producto de la concepción desde la fecundación del óvulo hasta el final de la décimo segunda semana de la gestación.Feto: El producto de la concepción desde el principio de la decimotercera semana de la gestación hasta su expulsión o extracción. Los siguientes artículos de la Ley General de Salud de acuerdo a los términos antes mencionados notifican el siguiente informe.

Art. 42: En investigaciones de riesgo certificar que las mujeres no estén embarazadas. 
Art. 43: El consentimiento informado se podrá dispensar cuando exista un riesgo inminente para la salud o la vida del embrión o feto.

Art. 45: Las investigaciones sin beneficio terapéutico no deberán representar un riesgo mayor al mínimo para el embrión o feto.

Art. 46: Investigación no relacionada con el embarazo, pero con beneficio terapéutico para la mujer, no deberán exponer al embrión o feto.

Art. 47: Las investigaciones en mujeres embarazadas con beneficio terapéutico relacionado con el embarazo se permiten cuando estén encaminadas a incrementar la viabilidad de feto.

Art. 52: Los fetos serán sujetos de investigación solamente si las técnicas y medios utilizados proporcionan la máxima seguridad para ellos y la embarazada.

Éstos son los artículos y apartados de las diferentes leyes, reglamentos y códigos que las enfermeras tienen que faltar y omitir cuando se vean en la necesidad de participar en la realización de un aborto en los hospitales del Departamento del Distrito Federal. Si bien la modificación de ley que fue reformada la protege legalmente, moral y éticamente qué pasará con la conciencia y el actuar con apego a la ética personalista, resultará en un cargo de conciencia por colaborar en la consecución de un daño a un inocente, y sin derecho de tener la objeción de conciencia, ya que sí sería sancionada por este hecho.

\section{Identificar los valores involucrados}

Persona humana. Es el primer y más primordial valor que se ve involucrado, ya que la falta de respeto por la persona y la ignorancia de cuándo el embrión es persona hace que no se tenga un criterio ético para el respeto a la persona y por lo tanto apoyar una ley que es, como ya lo analizamos antes, anticonstitucional.

Dignidad de la persona humana. El optar por velar por los intereses de las mujeres, ignorando la dignidad del embrión humano es faltar a uno de los valores principales de la ética: el respeto a la dignidad de la persona.

Prudencia. Con la despenalización del aborto se omite la prudencia, ya que no existe el entendimiento que dirija el acto. Fortaleza. Igual que la prudencia se omite ya que no existe voluntad por hacer el bien; al contrario, se realiza un mal. Templanza. No se actuó con ella ya que se voto visceralmente y con prejuicios partidistas y populistas.

Justicia. Fue uno de los valores en los que menos se reflexionó, ya que no existe justicia para alguien que no tiene voz como el embrión.

La acción humana. A quien realice o colabore para quitar la vida a un ser humano, antes de nacer, para eliminarlo con el fin del bienestar de la mujer que lo solicite. Desde luego que este acto no es ético, ni el fin ni las circunstancias.

Fin del ser humano. Si lo que busca todo ser humano es la felicidad y el bienestar, el quitar la vida a un inocente no tiene nada que ver con la felicidad, ni de la persona que lo realiza ni a quien se lo realizan.

Libertad. Al embrión no se le da la oportunidad de elegir, por lo tanto no se respeta su libertad; así mismo, no se respeta la libertad de elección de las personas involucradas cuando una mujer solicite un aborto.

\section{Jerarquización de valores}

$1^{\circ}$ Ante todo la persona, ya que siendo persona de ella emanan todos los valores y principios.

$2^{\circ}$ La dignidad de la persona. Está inmersa en el respeto a la persona, ya que todo ser humano merece ser tratado dignamente por el solo hecho de ser persona.

$3^{\circ} \mathrm{El}$ fin de la persona. El acto no es bueno porque el fin no lo es, ya que se optó por la muerte del embrión.

$4^{\circ}$ Libertad. Porque el respeto a la persona da la elección de escoger entre dos bienes, pero en este caso se ignoró la libertad del embrión, si bien se respetó la libertad de quien elige el aborto; este fin no se justifica.

$5^{\circ}$ Justicia. Este valor hace referencia a dar a cada quien lo que le corresponde; sin embargo, al embrión no se le respetó, desde el hecho de que decidieron por él.

$6^{\circ}$ Prudencia. El entendimiento no estuvo dirigido a hacer el bien.

$7^{\circ}$ Fortaleza. No existe ya que no se hace fuerte para actuar con voluntad de hacer un bien, para el no nacido.

$8^{\circ}$ Templanza. Se actuó visceralmente y sin prejuicios en contra del más débil.

\section{COTEJAR CON LOS PRINCIPIOS DE LA ÉTICA PERSONALISTA Y LOS PRINCIPIOS FORMALES}

\section{Principios de la ética personalista}

El valor de la corporeidad. Al votar a favor de la abolición de la pena del aborto, se le está ignorando como persona, y se le deja de lado su corporeidad, ya que se le da un valor como persona sólo hasta las doce semanas de gestación; no se toma en cuenta que el embrión es persona desde su fecundación, así que se ignora su corporeidad y se cosifica restándole valor.

Defensa de la vida física. No existe ningún respeto por la vida, antes de las doce semanas, lo que conlleva a decidir por la vida del embrión antes de esta fecha, y por lo tanto no se respeta el fundamental principio de la ética personalista. 
Respeto a la libertad con responsabilidad. No existe respeto de la libre elección del bien o del mal por parte del embrión, y tampoco existe libertad de actuación del personal que tiene que atender las solicitudes de las mujeres por el aborto.

Principio terapéutico. Este principio no es aplicado ya que se está actuando para producir un mal al embrión, si bien la solicitante es la madre de éste, y aparentemente el acto será terapéutico para ella, no se toma en cuenta ni la dignidad ni la corporeidad del embrión, por lo tanto se falta a este principio.

Principio de solidaridad/subsidiaridad. La práctica del aborto no es solidaria ya que sólo se persigue un "bien particular", el de subsidiariedad; está ignorada ya que no se le brindó ningún apoyo al más débil, en este caso el embrión.

\section{PRINCIPIOS FORMALES}

Sindéresis. No se evita el mal y el "bien" sólo se hace con la mujer solicitante del aborto; el equipo de salud está obligado a actuar en contra del embrión.

Integridad. El bien de la mujer no justifica la muerte del embrión.

Antrópico. Por medio de este principio, todo lo que cambió la Asamblea Legislativa es ilegal.

Universalidad. El principio más universal es el respeto a la vida y en este caso no se respeta.

Virtud. El bien del embrión es obligatorio, pero la despenalización del aborto hace legal el mal del mismo.

Indisponibilidad. Para los legisladores, se puede disponer de la vida del embrión.

No permisivismo. Un claro ejemplo de este principio es la despenalización del aborto, ya que es malo prohibir lo bueno, no se respeta la dignidad ni la vida del embrión, sólo se le hace el "bien" a la madre de éste.

Mal menor. Se realiza el aborto como un mal menor, ya que la madre lo solicita; sin embargo, esta acción es contraria a este principio.

Totalidad. El embrión es un ser humano desde su concepción y no desde la semana doce de gestación; es un todo desde que es fecundado.

\section{Valoración moral}

Acto. Éste se realiza sin tomar en cuenta la corporeidad del embrión, así como su dignidad de ser una persona desde que se realiza la fecundación; el aborto se realiza estando consciente de que se actúa contrario a la ética y bioética, por lo tanto es moralmente malo.

Fines. El fin es sólo uno: acabar con la vida del embrión, para resguardar el bienestar materno, el fin no justifica los medios.
Circunstancias. Aunque los argumentos de la madre puedan ser válidos para no querer tener a su hijo, las circunstancias son éticamente malas, sea cual sea el motivo de abortar. Valores y principios. Todos los valores y principios que intervienen en el acto del aborto, son pasados por alto, si no se respeta el principio fundamental de la bioética personalista, que es el respeto a la vida.

Identificar las posibilidades. Sólo existe una posibilidad, que de ahí se puede desglosar el respeto a todos los valores y principios, y es el respeto a la vida; los legisladores deben de hacerse conscientes de que optaron por legalizar un asesinato. La única posibilidad es que la Suprema Corte de Justicia revoque la ley. También se podría optar por orientar a las mujeres que solicitan el aborto, que sería la adopción de esos bebés y darles la posibilidad de vivir.

Optar por lo válido. Lo válido en este caso es abocarse a los principios de la ética personalista, respetando la vida y la dignidad del embrión humano, reconociendo su corporeidad y su esencia, desde el momento mismo de la fecundación; este reconocimiento revocaría todas las reformas que hasta ahora se hicieron en la Asamblea Legislativa del D. F., ya que a su vez reconocerían todas las leyes, que han violado con la reforma del Código Penal acerca del aborto.

Tomar una decisión. Lo válido es el respeto a la vida, la persona y su dignidad; por lo tanto, el aborto es moralmente malo; sin embargo, los profesionales de enfermería y el personal sanitario obligado a realizarlo, está en una encrucijada, ya que si bien deben respetar sus principios y convicciones, a su vez corren el riesgo de ser sancionados por las autoridades si se niegan a cooperar con la asistencia del aborto.

\section{CONCLUSIONES}

Es imperativo reflexionar ampliamente sobre la decisión de los legisladores acerca de la despenalización del aborto en el D. F., ya que como se ha analizado anteriormente, violan un sinnúmero de leyes tanto nacionales como internacionales, además de faltar a los más fundamentales principios de la bioética, como son el respeto a la vida y la dignidad de la persona. ¿Dónde quedó el deber moral de los diputados, que aprueban una reforma de ley anticonstitucional, pero sobre todo que atenta contra lo más excelso que tiene el ser humano que es la vida, esto sin tomar en cuenta que resultan afectados un gran número de profesionales, entre ellos de enfermería, obligándolas a participar de una acto sin tomar en cuenta sus creencias y su formación profesional que está encaminada a proteger la vida y preservar la salud? En todo caso, si se decide por la no procreación existe un sinnúmero de métodos para lograrlo, y si bien la decisión es únicamente responsabilidad de quien decide practicarse el aborto, esa 
misma decisión pudo haberla tomado desde antes de la concepción, situación que fundamentaría tomar acciones de educación y prevención antes de la curación (aborto), como es lo clásico en nuestro actual sistema de salud. En esta situación, el papel educador de los profesionales de enfermería sería la piedra angular para lograrlo. Tomando en cuenta que lo anterior no atenta contra las creencias ni la bioética en que son formados los profesionales de enfermería y se respetaría el primer y más excelso derecho que tiene la persona a ser reconocido como humano y su derecho, por ende, a la vida.

\section{BIBLIOGRAFÍA}

1. Kerouac $\mathrm{S}$ et al. El pensamiento enfermero.

2. Marriner TA, Raile AM. Modelos y teorías de enfermería.
3. Martínez MP. Análisis sobre el comienzo de la vida. Cuadernos de Bioética 200/2a $3^{\mathrm{a}}$. p 281.

4. Guerra LR. Hacia una ontología del embrión humano. Ponencia del Tercer Congreso Internacional de la Federación Internacional de los Centros e Instituciones de Bioética de Inspiración Personalista. 29 de septiembre del 2005, México, D.F. p 2.

5. Andorno R. La dimensión biológica de la personalidad humana: El debate sobre el estatuto del embrión. Cuadernos de Bioética. 2004/1ª p 31.

6. Guerra L. Op. cit. p 1.

7. Op. Cit. Andorno: 30.

8. Serra A. El embrión humano: ¿Una "masa de células" disponibles o un "ser humano"? Medicina y Ética 2002/2. p 125.

9. ÍBIDEM p:31.

10. Martínez. Op. cit. p. 278.

11. Serra. Op. cit. p. 126.

12. Publicaciones del 20 y 22 de abril de 2007. http://www.eluniversal.com.mx

13. Bellver CV. ¿Existe una ética universal? Bioética y Derechos. Cuadernos de Bioética 2004/3 p. 438.

14. Cfr. Melgar RJ. Objeción de conciencia y farmacia. "Cuadernos de Bioética" 14 (1993), p. 37. 